\title{
Correction to: Development and Optimization of Clinical Informatics Infrastructure to Support Bioinformatics at an Oncology Center
}

\section{Randa M. Perkins and Joseph Markowitz}

\section{Correction to:}

Chapter 1 in: Joseph Markowitz (ed.), Translational Bioinformatics

for Therapeutic Development, Methods in Molecular Biology, vol. 2194, https://doi.org/10.1007/978-1-0716-0849-4_1

The book has been inadvertently published with wrong affiliation for the corresponding author, Randa M. Perkins, of chapter 1. It has now been updated as below in this revised version of the book.

"Department of Cutaneous Oncology, University of South Florida, Morsani College of Medicine, Tampa, FL, USA" has been revised as "Department of Oncologic Sciences, University of South Florida, Morsani College of Medicine, Tampa, FL, USA”.

The updated online version of this chapter can be found at:

https://doi.org/10.1007/978-1-0716-0849-4_1 